\title{
Antimicrobial susceptibility profiles of Staphylococcus spp. contaminating raw goat milk
}

\author{
Abimael E. Silva Júnior ${ }^{1}$ D , Priscylla C. Vasconcelos ${ }^{1}$ D, Mauro M. S. Saraiva1 ${ }^{\mathbb{D}}$, Lauro Santos Filho ${ }^{(\mathbb{D})}$,
} Núbia M. V. Silva1 ${ }^{1}$, Patricia E. N. Givisiez ${ }^{1}$ id and Celso J. B. Oliveira ${ }^{1}$ (D)

1. Department of Animal Science, College for Agricultural Sciences, Federal University of Paraiba, Brazil; 2. Department of Pharmaceutical Sciences, College of Health Sciences, Federal University of Paraiba, Brazil.

Corresponding author: Celso J. B. Oliveira, e-mail: celso.oliveira@academico.ufpb.br

Co-authors: AESJ: estevamabimael@gmail.com, PCV: pczootecnista.1@gmail.com, MMSS: saraiva_ufba@hotmail.com, LSF: lauro.ufpb@hotmail.com, NMVS: nubia274@gmail.com,PENG: patricia@cca.ufpb.br

Received: 08-07-2020, Accepted: 17-03-2021, Published online: 05-05-2021

doi: www.doi.org/10.14202/vetworld.2021.1074-1079 How to cite this article: Silva Júnior AE, Vasconcelos PC, Saraiva MMS, Santos Filho L, Silva NMV, Givisiez PEN, Oliveira CJB (2021) Antimicrobial susceptibility profiles of Staphylococcus spp. contaminating raw goat milk, Veterinary World, 14(5): 1074-1079.

\begin{abstract}
Background and Aim: Antimicrobial resistance poses a major threat to global public health. Foodstuff of animal origin can serve as potential vehicles for the dissemination of antimicrobial-resistant bacteria and resistance genes to consumers. In view of the lack of knowledge about antimicrobial resistance in bacteria associated with goat milk, the aim of this study was to report species-level identification and antimicrobial susceptibility profiles of a large collection of Staphylococcus spp. isolates recovered from raw goat milk in Brazil.

Materials and Methods: A total of 434 Staphylococcus spp. isolates originated from 510 goat milk samples in Northeast Brazil were investigated. The isolates were obtained by conventional microbiological methods. Species identification and antimicrobial susceptibility testing were performed by means of a semi-automated system using a panel for biochemical tests and broth microdilution method for 19 antimicrobial drugs.

Results: Although Staphylococcus aureus (22.6\%) accounted for the majority of the isolates, a total of 13 different nonaureus staphylococci spp. were identified. High resistance rates against erythromycin (40.8\%), and the beta-lactams ampicillin (45.9\%) and penicillin (42.9\%) were observed among S. aureus isolates. The most significant findings were related to the resistance against quinupristin-dalfopristin, a drug of last resort used in human medicine to treat infections caused by vancomycin-resistant $S$. aureus and enterococci.

Conclusion: The high diversity of Staphylococcus spp. showing phenotypic resistance against different antimicrobial drugs encourages further investigations on the real impact of these bacteria as reservoirs of antimicrobial resistance genes to consumers. Furthermore, the potential impact of technological processes, such as pasteurization, fermentation, and maturation, on the maintenance and dissemination of antimicrobial resistance among the microbial populations in milk and dairy products must also be investigated.
\end{abstract}

Keywords: antimicrobial resistance, dairy goats, food safety, Staphylococcus.

\section{Introduction}

Paraiba is the leading goat milk producer state in Brazil, with a total production of 5.63 million litters, representing $23.9 \%$ of the revenue attributed to the whole Brazilian goat milk sector [1]. In Paraiba State, milk production is based on smallscale extensive or semi-extensive farming in semiarid regions, in which dairy goats are raised on native Caatinga vegetation (seasonal dry forest) and fed cactus pear (Opuntia ficus) as fodder [2]. As part of government programs to improve the agricultural sector in low-income areas, goat raw milk is purchased from smallholders, pasteurized in

Copyright: Silva Júnior, et al. Open Access. This article is distributed under the terms of the Creative Commons Attribution 4.0 International License (http://creativecommons.org/licenses/ by/4.0/), which permits unrestricted use, distribution, and reproduction in any medium, provided you give appropriate credit to the original author(s) and the source, provide a link to the Creative Commons license, and indicate if changes were made. The Creative Commons Public Domain Dedication waiver (http:// creativecommons.org/publicdomain/zero/1.0/) applies to the data made available in this article, unless otherwise stated. small-scale dairy plants, and distributed to schools and day care units [3].

Although dairy goat production plays an important socioeconomic role in low-income Northeast Brazil, very little is known regarding staphylococcal contamination in milk produced by smallholders in semi-arid Brazil. Besides, the fact that staphylococci are leading foodborne pathogens worldwide due to the capacity of some strains to produce toxins $[4,5]$, including heat-stable enterotoxins that can resist the pasteurization process [6], antimicrobial-resistant Staphylococcus spp. are of public health concern. Although the extensive use of antimicrobials in human medicine is a major driver for the emergence and dissemination of antimicrobial resistance [7], foodstuffs might play a potential role in the dissemination of antimicrobial-resistant bacteria and resistance genes to human populations consuming these products [8]. The emergence and dissemination of antimicrobial resistance in food bacteria are favored by increased selection pressure caused by the extensive 
use of antimicrobial drugs in food animal production systems [9]. Subclinical intramammary infections caused by Staphylococcus spp., the most common disease affecting the dairy industry worldwide [10], are associated with continuous use of antibiotics in dairy cattle [11]. However, information on antimicrobial resistance levels in Staphylococcus associated with intramammary infections in goats is limited [12]. Another critical limitation is the lack of knowledge on the spp. of Staphylococcus associated with milk and dairy products, as the majority of the studies identify isolates as Staphylococcus aureus and non-aureus staphylococci (NAS) spp. The identification of the most frequent Staphylococcus spp. and the determination of their antimicrobial susceptibility rates are important for controlling and prevention purposes at both farm and industry levels [13].

Staphylococci are highly capable of acquiring resistance to several classes of drugs, including the highest priority critically important antimicrobials (HPCIA), which are drugs of last resort to treat serious bacterial infections in people[13]. Estimates of the economic impact of antimicrobial resistance to the global economy reach dreadful numbers. The World Bank announced that antimicrobial resistance could affect the global GDP by between 1.1 and $3.8 \%$ points by 2050 [14]. According to the World Economic Forum [15], the estimated costs for antimicrobial resistance can reach up to $\$ 100$ trillion by 2050 , and the number of deaths could exceed 300,000 people per year. Microbial contamination of animal-derived foods may occur directly through infected animals or may result from cross-contamination during processing, food transport, and storage [16,17]. Therefore, investigations on antimicrobial susceptibility patterns in food contaminating bacteria are important to monitor foodstuffs as potential vehicles for dissemination of antimicrobial resistance genes to consumers.

The aim of the present study was to investigate the most common spp. of Staphylococcus contaminating goat milk and to assess their susceptibility profiles against antimicrobials, including some drugs commonly used in human medicine to treat staphylococcal infections.

\section{Materials and Methods}

\section{Ethical approval and Informed consent}

Ethics approval was not required for this study. Verbal consent was obtained from farmers allowing milk samples to be collected during routine milking procedures.

\section{Study period and location}

The milk samples were collected from Cariri region, Paraíba State, Northeastern Brazil from March 2015 to February 2016. Milk samples were processed at the Laboratory for Animal-derived Foods (LAPOA) of the College for Agricultural Sciences, Federal University of Paraíba (CCA/UFPB).

\section{Study design}

Staphylococcus spp. isolates originated from goat milk $(n=434)$ were investigated in this study. The isolates were recovered from 510 milk samples collected in Cariri, a semi-arid region in Paraiba State, Northeast Brazil. Samples $(10 \mu \mathrm{L})$ were streaked onto Baird Parker agar (HiMedia, India) and incubated at $37^{\circ} \mathrm{C}$ for $24-48 \mathrm{~h}$ Colonies showing typical and non-typical Staphylococcus characteristics were tested for catalase, oxidase and examined microscopically after conventional Gram staining procedure. Confirmed Staphylococcus isolates were further identified by means of a biochemical panel (Combo PC33, Siemens Healthcare, Germany), including the following tests: Crystal violet reaction, nitrate reduction, novobiocin resistance, Voges-Proskauer, sensitivity to optochin, alkaline phosphatase, bile esculin, production of pyrrolidone, dehydrolyzation of arginine, breakage of arginine, glycosidase production, hydroxylation of indoxyl phosphatase, urea, phenol red, growth at $6.5 \% \mathrm{NaCl}$, bacitracin resistance, use of pyruvate, presence of $\beta$-lactamase, and hemolysis. Species identification was based on automatic interpretation of the biochemical test results by AutoScan 4 software (Siemens Healthcare, Germany).

\section{Antimicrobial susceptibility test}

Phenotypic antimicrobial susceptibility was assessed by means of a semi-automated microdilution method (Autoscan4, Siemens Healthcare) for the following drugs and their respective cutoff values $(\mu \mathrm{g} / \mathrm{mL})$ : Ampicillin/sulbactam (Sam) $(\geq 32 / 16)$; ampicillin (Amp) $(\geq 0.5)$; amoxicillin/clavulanate de $\mathrm{K}(\geq 8 / 4)$; ceftriaxone $(\geq 64)$; clindamycin (Cli) $(\geq 4)$; ciprofloxacin (Cip) ( $\geq 4)$; daptomycin (Dap) $(\geq 2)$; erythromycin (Eri) ( $\geq 8)$; gentamicin (Gen) ( $\geq 16)$; nitrofurantoin ( $\geq 128)$; quinupristin/dalfopristin (QD) $(\geq 4)$; levofloxacin (Lvx) ( $\geq 8)$; linezolid (Lzd) ( $>4)$; moxifloxacin (Mxf) ( $\geq 8)$; oxacillin (Oxa) $(\geq 0.5$ para $\mathrm{SCN}$ e $\geq 4$ para $S$. aureus/Staphylococcus lugdunensis); penicillin (Pen) $(\geq 0.25)$; rifampin (Rif) $(\geq 4)$; trimethoprim/sulfamethoxazole (Sxt) $(\geq 4 / 76)$; and tetracycline (Tet) $(\geq 16)$. The interpretation of the results was performed according to the Clinical and Laboratory Standards Institute criteria [18]. S. aureus ATCC 25923 was used as control.

Isolates showing susceptibility to all drugs were considered pan-susceptible and those resistant to three or more different antimicrobial classes were considered multidrug-resistant (MDR) isolates [19].

\section{Results}

S. aureus $(\mathrm{n}=98 ; 22.6 \%)$ and Staphylococcus epidermidis $(\mathrm{n}=71 ; 16.4 \%)$ were the most frequent $\mathrm{spp}$. cultured from raw goat milk (Table-1). A total of 13 different spp. of coagulase-negative staphylococci were identified in goat milk samples. The high frequency of Staphylococcus hyicus spp. $(\mathrm{n}=22 ; 5.1 \%)$ is noteworthy. Table-2 shows absolute and relative frequencies of antimicrobial susceptibility of $S$. aureus and NAS. 
Pan-susceptibility was observed in 155 (35.7\%) isolates. Interestingly, we detected NAS showing resistance to the highest priority critically important antimicrobials that are used exclusively to treat skin and urinary tract infections in humans $[20,21]$.

In our study, $4.1 \%$ of $S$. aureus and $6.3 \%$ of NAS isolates were resistant to amoxicillin/clavulanate. We also detected resistance against QD among the NAS. This group showed higher resistance rates against $\mathrm{Cli}$ and Eri $(\mathrm{p}<0.05)$ than S. aureus.

Table-3 shows the frequency of MDR profiles among Staphylococcus spp. isolated from goat milk. A

Table-1: Coagulase-positive Staphylococcus and coagulase-negative Staphylococcus spp. cultured from raw goat milk from Northeast Brazil.

\begin{tabular}{lcc}
\hline Staphylococcus spp. & Number of isolates & \% \\
\hline Staphylococcus aureus & 98 & 22.6 \\
Staphylococcus hyicus & 22 & 5.1 \\
Staphylococcus intermedius & 41 & 9.4 \\
Staphylococcus epidermidis & 71 & 16.4 \\
Staphylococcus simulans & 46 & 10.6 \\
Staphylococcus haemolyticus & 32 & 7.4 \\
Staphylococcus hominis & 14 & 3.2 \\
subsp. hominis & & \\
Staphylococcus saprophyticus & 10 & 2.3 \\
Staphylococcus lugdunensis & 16 & 3.7 \\
Staphylococcus sciuri & 21 & 4.8 \\
Staphylococcus schleiferi & 21 & 4.8 \\
subsp. schleiferi & & \\
Staphylococcus cohnii subsp. & 07 & 1.6 \\
cohnii & & \\
Staphylococcus xylosus & 16 & 3.7 \\
Staphylococcus auricularis & 09 & 2.1 \\
Staphylococcus warneri & 09 & 2.1 \\
Staphylococcus cohnii subsp. & 01 & 0.2 \\
urealyticum & & \\
Total & 434 & 100 \\
\hline
\end{tabular}

total of 134 (30.9\%) MDR isolates were detected. One $S$. aureus isolate was resistant to 14 drugs (Sam, Amp, Dap, Lvx, Mxf, Rif, Syn, Cli, Cip, Eri, Gen, Lzd, Oxa, Pen, Sxt, and Tet).

\section{Discussion}

The high occurrence of $S$. aureus in our study was expected as this species is commonly isolated from dairy animals worldwide. Nonetheless, this finding is of public health significance, as $S$. aureus is among the main Staphylococcus species causing food poisoning in humans due to the production of heat-stable enterotoxins [6]. The observed high frequency of S. hyicus among the goat milk samples in the present study is surprising, since $S$. hyicus has not been commonly detected in milk. Considering that $S$. hyicus originates from skin sources [22], the high occurrence of this spp. in milk could be related to hygiene deficiencies in teat cleaning and disinfection during milking practices [23] that can also increase overall milk contamination. This is corroborated by the fact that some species commonly associated with skin infections in both animals and humans [24] were detected in our study, such as Staphylococcus xylosus, Staphylococcus schleiferi, and Staphylococcus simulans, and have been reported as emerging zoonotic pathogens [25-27].

S. aureus, S. epidermidis, and S. hyicus are leading pathogenic staphylococci in veterinary medicine [28]. In dairy goats, $S$. epidermidis, $S$. simulans, and $S$. xylosus have been commonly isolated from intramammary infections $[12,29,30]$. The high frequency of $S$. epidermidis in our study is in accordance with a recent study in Mexico [31] reporting this organism as the main Staphylococcus spp. cultured from goat milk. $S$. epidermidis high frequency in goat milk has also been

Table-2: Antimicrobial susceptibility profiles of Staphylococcus aureus and non-aureus staphylococci isolated from goat milk in Paraiba State, Northeast Brazil.

\begin{tabular}{lccc}
\hline Class & Antimicrobials & Staphylococcus aureus (\%) & Non-aureus staphylococci (\%) \\
\hline Beta-lactams & Amp & $45(45.9)$ & $123(36.6)$ \\
& Pen & $42(42.9)$ & $136(40.5)$ \\
& Oxa & $17(17.4)$ & $67(19.9)$ \\
Beta-lactam/beta-lactamase & Cro & $7(7.1)$ & $17(5.1)$ \\
inhibitors & Amc & $4(4.1$ & $47(6.3)$ \\
Sulfonamides & Sam & $11(11.2)$ & $25(7.4)$ \\
Fluoroquinolones & Sxt & $3(3.1)$ & $37(11.0)$ \\
& Lvx & $6(6.1)$ & $11(3.3)$ \\
Lipopeptides & Mxf & $4(4.1)$ & $21(6.3)$ \\
Nitrofurantoin & Cip & $8(8.2)$ & $63(18.8)$ \\
Ansamycins & Dap & $16(16.3)$ & $23(6.9)$ \\
Streptogramins & Nft & $1(1.0)$ & $39(11.6)$ \\
Lincosamides & Rif & $10(10.2)$ & $42(12.5)$ \\
Macrolides & QD & $9(9.2)$ & $99(29.5)$ \\
Aminoglycosides & Cli & $20(20.4)$ & $115(34.2)$ \\
Oxazolidines & Eri & $40(40.8)$ & $27(8.0)$ \\
Tetracyclines & Gen & $13(13.3)$ & $36(10.7)$ \\
\hline
\end{tabular}

Sam=Ampicillin/sulbactam; Amp=Ampicillin; Amc=Amoxicillin/clavulanate de K; Cro=Ceftriaxone; Clindamycin; Cip=Ciprofloxacin; Dap=Daptomycin; Eri=Erythromycin; Gen=Gentamicin; Nft=Nitrofurantoin; QD=Quinupristin/ dalfopristin; Lvx=Levofloxacin; Lzd=Linezolid; Mxf=Moxifloxacin; Oxa=Oxacillin; Pen=Penicillin; Rif=Rifampin; Sxt=Trimethoprim/sulfamethoxazole; Tet=Tetracycline 
Table-3: Multidrug-resistant Staphylococcus aureus and non-aureus staphylococci spp. isolated from goat milk in Paraiba State, Northeast Brazil.

\begin{tabular}{lcc}
\hline $\begin{array}{l}\text { Number } \\
\text { of drug } \\
\text { classes }\end{array}$ & $\begin{array}{c}\text { MDR } \\
\text { Staphylococcus } \\
\text { aureus (\%) }\end{array}$ & $\begin{array}{c}\text { MDR non-aureus } \\
\text { staphylococci } \\
(\%)\end{array}$ \\
\hline 3 & $5(5.1)$ & $32(9.5)$ \\
4 & $8(8.2)$ & $11(3.3)$ \\
5 & $0(0.0)$ & $9(2.7)$ \\
6 & $2(2.0)$ & $10(2.9)$ \\
7 & $5(5.1)$ & $18(5.3)$ \\
8 & $5(5.1)$ & $10(2.9)$ \\
9 & $0(0.0)$ & $7(2.0)$ \\
10 & $1(1.0)$ & $4(1.2)$ \\
11 & $1(1.0)$ & $5(1.5)$ \\
12 & $0(0.0)$ & $1(0.3)$ \\
Total & 27.5 & 31.6 \\
\hline
\end{tabular}

MDR=Multidrug-resistant

reported in previous studies, possibly associated with subclinical mastitis in dairy goats [29].

According to a previous investigation on the antimicrobial susceptibility of a large set of $S$. aureus from foodstuffs (1150 samples), the highest resistance rates were observed against Pen $(83 \%)$, Lzd (67.7\%), and Eri (52.1\%); however, significant differences were observed according to the type of food [32].

The detection of $S$. aureus and NAS resistance to amoxicillin/clavulanate suggests that some Staphylococcus strains found in raw goat milk can harbor different resistance mechanisms, such as serine- $\beta$-lactamase production, including extended-spectrum $\beta$-lactamases that could hydrolyze later-generation cephalosporins and carbapenemases. Thus, NAS can be considered reservoirs of antimicrobial resistance, although $S$. aureus has been considered the key spp. involved in both food poisoning outbreaks and clinical infections in humans. This is also corroborated by the high resistance rates observed in NAS isolated from food animal sources, particularly resistance against macrolides, Tet, and streptogramins [33].

Considering that quinupristin is a drug of last resort used to treat infections caused by vancomycin-resistant $S$. aureus and enterococci, and these are among the most rapidly growing multidrug-resistant bacteria affecting humans [34], further investigations on the quinupristin resistance mechanisms, these isolates are warranted.

Tet has been commonly used for therapeutic purposes on farm animals for decades and high rates of resistance against this drug have been observed among different organisms, including pathogenic bacteria [35].

The real impact of antimicrobial-resistant Staphylococcus spp. contaminating goat milk on the putative dissemination of antimicrobial resistance to humans is beyond the scope of this study. However, considering that pasteurization is a mild heat treatment, and the fact that milk is a suitable medium for the maintenance and growth of bacteria, it is plausible to consider that milk can serve as source of antimicrobial resistance genes to the human gut microbiota, supporting previous assumptions [36,37]. The rationale for this is based on the many mechanisms of horizontal transference of antimicrobial resistance genes among bacteria, such as plasmids, transposons, and integrons.

Finally, staphylococci can serve as reservoirs of antimicrobial resistance genes to milk microorganisms. A large number of antimicrobial resistance genes have been identified in lactic acid bacteria [38,39]. Increased rates of antimicrobial resistance in lactobacilli and related bacteria can pose a risk to consumers as they can disseminate resistance genes to pathogenic bacteria.

\section{Conclusion}

The high antimicrobial resistance rates in $S$. aureus and NAS in goat milk produced in the investigated region reveal the potential role of milk as a reservoir of antimicrobial resistance genes. The findings encourage further investigation of putative effects of technological processes, such as pasteurization, fermentation, and maturation, on the maintenance and dissemination of antimicrobial resistance genes in the microbiota of goat milk and dairy products. Such knowledge could be important to mitigate the spread of antimicrobial resistance in the dairy industry. Finally, our results highlight the importance of on-herd hygiene measures to reduce microbial contamination in milk produced by smallholders and the continuous awareness of producers toward antimicrobial stewardship.

\section{Authors' Contributions}

CJBO and LSF: Study conception and design. AESJ, MMSS, NMVS, and PCV Acquisition of data, analysis and interpretation of data. PENG, AESJ and LSF: Drafting of the manuscript: PENG, NMVS and CJBO: Supervision. PENG and CJBO: Critical revision. All authors read and approved the final manuscript.

\section{Acknowledgments}

This study was funded in part by the Coordenação de Aperfeiçoamento de Pessoal de Nível Superior (CAPES), Finance code 001. The authors are also thankful to Conselho Nacional de Pesquisa e Desenvolvimento (CNPq) for providing funds.

\section{Competing Interests}

The authors declare that they have no competing interests.

\section{Publisher's Note}

Veterinary World remains neutral with regard to jurisdictional claims in published institutional affiliation. 


\section{References}

1. IBGE. (2017) Instituto Brasileiro de Geografia e Estatística. Diretoria de Pesquisas. Coordenação de População e Indicadores Sociais. Coordenação de População e Indicadores Sociais. Available from: https://www.cidades. ibge.gov.br/brasil. Retrieved on 18-08-2020.

2. Sá, W.C.C., Santos, E.M., Oliveira, J.S. and Perazzo, A.F. (2017). Production of spineless cactus in Brazilian semiarid. In: Edva, R.L., Bezerra, L., editors. New Perspectives in Forage Crops. IntechOpen, London.

3. Food and Agriculture Organization. (2009) A Reference for Designing Food and Nutrition Security Policies: The Brazilian Fome Zero strategy. FAO Regional Office for Latin America and the Caribbean. Food and Agriculture Organization, Santiago. p23. Available from: http:// www.internationaloffice.unicamp.br/english/wp-content/ uploads/2015/02/FOME-ZERO-FAO-RLC-2009.pdf. Retrieved on 11-08-2020.

4. Hennekinne, J.A., De Buyser, M.L. and Dragacci, S. (2012) Staphylococcus aureus and its food poisoning toxins: Characterization and outbreak investigation. FEMS Microbiol. Rev., 36(4): 815-836.

5. Gucukoglu, A., Cadirci, O., Terzi, G., Kevenk, T.O. and Alisarli, M. (2013) Determination of enterotoxigenic and methicillin-resistant Staphylococcus aureus in ice cream. $J$. Food Sci., 78(5): M738-M741.

6. Kadariya, J., Smith, T.C. and Thapaliya, D. (2014) Staphylococcus aureus and staphylococcal foodborne disease: An ongoing challenge in public health. Biomed Res. Int., 2014: 827965.

7. Tacconelli, E. and Pezzani, M.D. (2019) Public health burden of antimicrobial resistance in Europe. Lancet Infect. Dis., 19(1): 4-6.

8. Wielinga, P.R., Jensen, V.F., Aarestrup, F.M. and Schlundt, J. (2014) Evidence-based policy for controlling antimicrobial resistance in the food chain in Denmark. Food Control, 40: 185-192.

9. Silbergeld, E.K., Graham, J. and Price, L.B. (2008) Industrial food animal production, antimicrobial resistance, and human health. Annu. Rev. Public Health, 29: 151-169.

10. Rainard, P., Foucras, G., Fitzgerald, J.R., Watts, J.L., Koop, G. and Middleton, J.R. (2018) Knowledge gaps and research priorities in Staphylococcus aureus mastitis control. Transbound. Emerg. Dis., 65(1): 149-165.

11. Gomes, F. and Henriques, M. (2016) Control of bovine mastitis: Old and recent therapeutic approaches. Curr. Microbiol., 72(4): 377-382

12. França, C.A., Peixoto, R.M., Cavalcante, M.B., Melo, N.F., Oliveira, C.J.B., Veschi, J.L.A., Mota, R.A. and Costa, M.M. (2012) Antimicrobial resistance of Staphylococcus spp. from small ruminant mastitis in Brazil. Pesq. Vet. Bras., 32(8): 747-753.

13. Rizek, C.F., Matte, M.H., Dropa, M., Mamizuka, E.M., Almeida, L.M., Lincopan, N., Matté, G.R. and Germano, P.M.L. (2011) Identification of Staphylococcus aureus carrying the mecA gene in ready-to-eat food products sold in Brazil. Foodborne Pathog. Dis., 8(4): 561-563.

14. World Bank. (2017) International Bank for Reconstruction and Development. Retrieved from Annual Report 2017. World Bank, Washington, DC Available from: http://www. worldbank.org. Retrieved on 22-04-2021.

15. World Economic Forum. (2018) The Global Risks Report 2018. 13 ${ }^{\text {th }}$ ed. World Economic Forum, Cologny, Switzerland.

16. Normanno, G., La Salandra, G., Dambrosio, A., Quaglia, N.C., Corrente, M., Parisi, A., Santagada, G., Firinu, A., Crisetti, E. and Celano, G.V. (2007) Occurrence, characterization and antimicrobial resistance of enterotoxigenic Staphylococcus aureus isolated from meat and dairy products. Int. J. Food Microbiol., 115(3): 290-296.

17. Akindolire, M.A., Babalola, O.O. and Ateba, C.N. (2015)
Detection of antibiotic-resistant Staphylococcus aureus from milk: A public health implication. Int. J. Environ. Res. Public Health, 12(9): 10254-10275.

18. Clinical and Laboratory Standard Institute. (2017) Performance Standards for Antimicrobial Susceptibility Testing. $27^{\text {th }}$ ed. Clinical and Laboratory Standard Institute, Waine, PA.

19. Schwarz, S., Silley, P., Simjee, S., Woodford, N., van Duijkeren, E., Johnson, A.P. and Gaastra, W. (2010) Assessing the antimicrobial susceptibility of bacteria obtained from animals. Vet. Microbiol., 141(1-2): 1-4.

20. Rybak, M.J., Hershberger, E., Moldovan, T. and Grucz, R.G. (2000) In vitro activities of daptomycin, vancomycin, linezolid, and quinupristin-dalfopristin against staphylococci and enterococci, including vancomycin intermediate and resistant strains. Antimicrob. Agents Chemother, 44(4): 1062-1066.

21. Huttner, A., Verhaegh, E.M., Harbarth, S., Muller, A.E., Theuretzbacher, U. and Mouton, J.W. (2015) Nitrofurantoin revisited: A systematic review and meta-analysis of controlled trials. J. Antimicrob. Chemother., 70(9): 2456-2464.

22. Foster, A.P. (2012) Staphylococcal skin disease in livestock. Vet. Dermatol., 23(4): 342-351, e63.

23. Swartz, T. and Petersson-Wolfe, V. (2016) Coagulasenegative Staphylococci and Staphylococcus hyicus: A Practical Summary for Controlling Mastitis. Dairy Specialist, Virginia Cooperative Extension. Virginia Polytechnic Institute and State University, Virginia.

24. Tzamalis, A., Chalvatzis, N., Anastasopoulos, E., Tzetzi, D. and Dimitrakos, S. (2013) Acute postoperative Staphylococcus schleiferi endophthalmitis following uncomplicated cataract surgery: first report in the literature. Eur. J. Ophthalmol., 23(3): 427-430.

25. Gozalo, A.S., Hoffmann, V.J., Brinster, L.R., Elkins, W.R., Ding, L. and Holland, S.M. (2010) Spontaneous Staphylococcus xylosus infection in mice deficient in NADPH oxidase and comparison with other laboratory mouse strains. J. Am. Assoc. Lab. Anim. Sci., 49(4): 480-486.

26. Davis, M.F., Cain, C.L., Brazil, A.M. and Rankin, S.C. (2013) Two coagulase-negative staphylococci emerging as potential zoonotic pathogens: Wolves in sheep's clothing? Front. Microbiol., 4: 123.

27. Shields, B.E., Tschetter, A.J. and Wanat, K.A. (2016) Staphylococcus simulans: An emerging cutaneous pathogen. JAAD Case Rep., 2(6): 428-429.

28. Aarestrup, F.M. and Schwarz, S. (2006) Antimicrobial resistance in staphylococci and streptococci of animal origin. In: Aarestrup, F.M, editor. Antimicrobial Resistance in Bacteria of Animal Origin. ASM Press, Washington, DC. p187-212.

29. Contreras, A., Sierra, D., Sánchez, A., Corrales, J.C., Marco, J.C., Paape, M.J. and Gonzalo, C. (2007) Mastitis in small ruminants. Small Ruminant. Res., 68(1): 145-153.

30. Salaberry, S.R.S., Saidenberg, A.B.S., Zuniga, E., Gonsales, F.F., Melville, P.A. and Benites, N.R. (2016) Microbiological analysis and sensitivity profile of Staphylococcus spp. in subclinical mastitis of dairy goats. Arq. Bras. Med. Vet. Zootec., 68(2): 336-344.

31. Martínez, S.P.M., Romero, R.A.R., Olivares, R.A.C., Ortiz, V.E.E. and Watty, A.E.D. (2018) Identification of and antimicrobial resistance in bacteria causing caprine mastitis in three states and a city in Central Mexico under manual and mechanical milking conditions. J. Dairy Vet. Anim. Res., 7(3): 115-118.

32. Wang, W., Baloch, Z., Jiang, T., Zhang, C., Peng, Z., Li, F., Fanning, S., Ma, A. and Xu, J. (2017) Enterotoxigenicity and antimicrobial resistance of Staphylococcus aureus isolated from retail food in China. Front. Microbiol., 8: 2256.

33. Bhargava, K. and Zhang, Y. (2012) Multidrug-resistant coagulase-negative staphylococci in food animals. J. Appl. 
Microbiol., 113(5): 1027-1036.

34. Hamel, A., Caillon, J., Jacqueline, C., Batard, E. and Potel, G. (2008) Efficacy of quinupristin/dalfopristin versus vancomycin, alone or in combination with rifampicin, against methicillin-resistant Staphylococcus aureus in a rabbit arthritis model. Int. J. Antimicrob. Agents, 31(2): 158-160.

35. Chopra, I. and Roberts, M. (2001) Tetracycline antibiotics: Mode of action, applications, molecular biology, and epidemiology of bacterial resistance. Microbiol. Mol. Biol. Rev., 65(2): 232-260.

36. Marshall, B.M. and Levy, S.B. (2011) Food animals and antimicrobials: Impacts on human health. Clin. Microbiol.
Rev., 24(4): 718-733.

37. Founou, L.L., Founou, R.C. and Essack, S.Y. (2016) Antibiotic resistance in the food chain: A developing country perspective. Front. Microbiol., 7: 1881.

38. Abriouel, H., Del Carmen Casado Muñoz, M., Lerma, L.L., Montoro, B.P., Bockelmann, W., Pichner, R., Kabisch, J., Cho, G., Franz, C.M.A., Gálvez, A. and Benomar, N. (2015) New insights in antibiotic resistance of Lactobacillus spp. from fermented foods. Food Res. Int., 78: 465-481.

39. Campedelli, I., Mathur, H., Salvetti, E., Clarke, S., Rea, M.C., Torriani, S., Ross, R.P., Hill, C. and O'Toole, P.W. (2019) Genus-wide assessment of antibiotic resistance in Lactobacillus spp. Appl. Env. Microbiol., 85(1): e01738-18.

$* * * * * * * *$ 